\title{
Dendritic Outgrowth of Myenteric Plexus Neurons in Primary Culture ${ }^{1}$
}

\author{
Michael W. Mulholland, M.D., Ph.D., Gail Romanchuk, M.S., and Kenneth Flowe, M.D. \\ Department of Surgery, Michigan Gastrointestinal Peptide Center, University of Michigan, Ann Arbor, Michigan $48109-0331$ \\ Presented at the Annual Meeting of the Association for Academic Surgery, Colorado Springs, Colorado, November 20-23, 1991
}

\begin{abstract}
Myenteric plexus neurons derived from neonatal guinea pigs, when exposed to serum, demonstrated a characteristic pattern of growth, including a proliferating outgrowth zone of glial cells, peripheral extension of dendritic processes, and progressive dendritic growth. Serum effects upon dendritic growth, measured morphometrically, was strongly dose- and temporally dependent. Dendritic density was increased 10fold $(120 \mathrm{hr})$ by the addition of $6 \%$ serum, while mean dendritic length was increased 3-fold. Development of cholinergic function was reflected by release of $\left[{ }^{3} \mathbf{H}\right] \mathrm{ACh}$ in response to cholecystokinin octapeptide, vasoactive intestinal peptide, substance $P$, and calcitonin gene-related peptide $\left(10^{-10}\right.$ and $\left.10^{-8} M\right)$. (C) 1992 Academic Press, Inc.
\end{abstract}

\section{INTRODUCTION}

Studies of mammalian enteric neural control mechanisms that use intact animals or in vivo models have distinct limitations. Neurotransmitters are secreted in minute quantities in the immediate proximity of target cells. Reuptake and enzymatic degradation of released neurotransmitters occurs rapidly within tissues, limiting the entry of such substances into the circulation and making correlation of circulating transmitter levels with local actions questionable. In addition, the microanatomic organization of the enteric nervous system interferes with the delivery of exogenous agents to target cells and with egress of endogenously secreted peptides.

Because of these factors, investigations that examine gastrointestinal function with appropriate in vitro techniques are likely to yield significant new insights. In this regard, enteric neurons in primary culture have utility for the study of enteric neurocrine function [1]. Potential advantages include: (1) biochemical measurements may be performed without interference from epithelial cells, surrounding smooth muscle, connective tissue, and endothelial cells; (2) neurons may be observed individually for assessment of morphology, intracellular peptide content, cellular growth, and intracellular ion fluxes;

\footnotetext{
${ }^{1}$ Supported by NIH Grant DK 41204.
}

and (3) neural plexuses may be observed without axonal input-being denervated from extrinsic nerves and also from other plexuses. Such a system would be well suited for study of the cellular mechanisms controlling neurotransmitter release. The model might also be adapted for investigation of trophic factors and developmental signals $[2,3]$.

The current study used primary cultures of guinea pig myenteric plexus neurons for investigations of enteric neuronal function. The specific aims were threefold: (1) to observe the morphological development of myenteric plexus neurons in primary culture, (2) to assess the role of trophic agents contained in serum in supporting neural growth and development, and (3) to demonstrate functional development as expressed by specific release of acetylcholine.

\section{MATERIALS AND METHODS}

Materials. The following materials were purchased: hemicholinium, collagenase, physostigmine, penicillin, streptomycin (Sigma Chemical, St. Louis, MO); substance $P$, calcitonin gene-related peptide, vasoactive intestinal peptide, cholecystokinin octapeptide, poly-L-lysine (Peninsula Labs, Belmont CA); medium 199 (GIBCO, Grand Island, NY); and NU-Serum (Collaborative Research, Bedford, MA). Neonatal Duncan-Hartley guinea pigs were purchased from Simonsen Labs (Gilroy, CA). Tritiated choline was obtained from New England Nuclear (Boston, MA).

Myenteric plexus neuronal culture. The culture method used is an adaptation of previously described methods [1, 2]. Two-day-old male Duncan-Hartley guinea pigs were used. The colon was exposed and, using aseptic technique, the longitudinal muscle of the taenia coli was dissected from the cecum. The lumen of the bowel was not entered. The taenia coli strips were divided into 5- to $6-\mathrm{mm}$ segments and transferred to a petri dish containing Hank's balanced salt solution (HBSS) with highly purified collagenase $(1 \mathrm{mg} / \mathrm{ml}$ ). Muscle strips were incubated at $4^{\circ} \mathrm{C}$ for $12 \mathrm{hr}$ and for 30 $\min$ at $37^{\circ} \mathrm{C}$. Tissue fragments were then transferred to fresh HBSS without collagenase and, under a dissecting microscope, loosely adherent smooth muscle fibers were 
dissected from the myenteric plexus, resulting in a purified neuronal plexus preparation.

For experiments in which neurons were cultured as explants in the form of plexuses, the tissue from each experimental animal was divided into 12 aggregates (approximately $5 \times 10^{3}$ neurons/aggregate). Plexuses were then placed in tissue culture wells (Costar) that had been previously coated with poly-L-lysine $(10 \mu \mathrm{g} / \mathrm{ml})$. For experiments in which the neurons were cultured in dispersed form, the plexuses were placed in microcentrifuge tubes containing trypsin $(3 \mathrm{mg} / \mathrm{ml})$ in PBS with 1 $\mathrm{m} M$ EDTA. After $25-\mathrm{min}$ incubation at $37^{\circ} \mathrm{C}$, the tissue was gently triturated with glass pipettes of decreasing bore size. The tissues were then centrifuged at $1500 \mathrm{rpm}$ for $5 \mathrm{~min}$ and the supernatant was replaced with appropriate culture medium. The cellular suspension was counted with a hemacytometer; $1.5 \times 10^{4}$ cells were added to each well of 24 -well culture plates (pretreated with poly-L-lysine) in a final volume of $500 \mu$ l of culture medium.

The cells were exposed to a defined culture medium in the absence or presence of various concentrations of serum. The defined medium was composed of medium 199 (serum-free) supplemented with nonessential amino acids $(10 \mathrm{mM})$, sodium pyruvate $(100 \mathrm{mM}), N$-2-hydroxyethylpiperazine- $N^{\prime}$-2-ethanesulfonic acid (Hepes) buffer $(10 \mathrm{~m} M)$, L-glutamine (200 $\mathrm{mM})$, glucose $(5 \mathrm{mg}$ / $\mathrm{ml})$, and penicillin-streptomycin solution $(100 \mathrm{U} / \mathrm{ml})$. For those experiments in which cells were exposed to serum, the defined culture medium was used to which was added NU-Serum at concentrations of $1,2,4,6$, or $10 \%$. Culture medium was changed every second day; antibiotics were omitted after the second day.

Assessment of morphological development. Cultures were examined using phase contrast microscopy. A visual record was maintained using photomicroscopy (Kodak TMax 400), and quantitative image analysis was performed daily. Dendritic growth was assessed in terms of the number of newly formed dendritic processes (dendritic density) and maximum dendritic extension (mean dendritic length). Plexuses were scored for length of peripheral dendritic growth by measuring the five longest, clearly separated dendritic processes per plexus. For each plexus, dendritic length was expressed as the mean of the five measurements. Dendritic density was expressed as the number of individual dendritic process extending circumferentially from each plexus. The individual performing morphometric analysis was unaware of the experimental conditions to which the cells had been exposed. To assess interassay variability, measurements were repeated at monthly intervals; variation was less than $10 \%$ in every instance.

Acetylcholine release studies. Acetylcholine release studies were performed using neurons cultured as plexuses in serum-containing medium after 5 to 7 days in culture. Plexuses were used only if they demonstrated extensive outgrowth of dendritic processes and were firmly adherent to the culture well.

Acetylcholine (ACh) release was examined using $\left[{ }^{3} \mathrm{H}\right] \mathrm{ACh}$ as a marker [4]. Neurons were exposed to $\left[{ }^{3} \mathrm{H}\right]$ choline $(0.2 \mu M$, sp act $80 \mathrm{Ci} / \mathrm{mmole})$ in oxygenated modified Krebs-Ringer buffer containing $50 \mu M$ physostigmine. Incubation with $\left[{ }^{3} \mathrm{H}\right]$ choline was performed for $60 \mathrm{~min}$ at $37^{\circ} \mathrm{C}$ in a Dubnoff metabolic incubator gassed with $95 \% \mathrm{O}_{2}-5 \% \mathrm{CO}_{2}$. After washing twice with fresh buffer, the tissues were recovered for $30 \mathrm{~min}$ before exposure to agonists. Each neuronal plexus was cxposed to only one agonist.

Total ${ }^{3} \mathrm{H}$ release was determined to indicate transmitter release. Exposure to agonists occurred in a release medium containing $118 \mathrm{mM} \mathrm{NaCl}, 4.7 \mathrm{mM} \mathrm{KCl}, 1 \mathrm{mM}$ $\mathrm{NaH}_{2} \mathrm{PO}_{4}, 0.5 \mathrm{mM} \mathrm{MgCl}, 2.5 \mathrm{mM} \mathrm{CaCl}_{2}, 25 \mathrm{mM}$ $\mathrm{NaHCO}_{3}, 11.1 \mathrm{mM}$ glucose, $50 \mu M$ physostigmine, and $10 \mu M$ hemicholinium. Labeled neurons were exposed to agonist in release medium for $15 \mathrm{~min}$ for determination of cumulative $\left[{ }^{3} \mathrm{H}\right] \mathrm{ACh}$ release. The medium was then aspirated and added to scintillation fluid. The tissue was solubilized, added to scintillation fluid, and counted separately.

Data analysis. All results were expressed as group means \pm SE. Each experiment was performed using the tissues of six to eight animals, and the sample size $(n=6$ or 8 ) was taken as the number of guinea pigs. Fractional release of $\mathrm{ACh}$ was calculated by expressing the radioactivity in the release medium as the percentage of total radioactivity in the tissue at the time of the experiment. The percentage of release of $\left[{ }^{3} \mathrm{H}\right] \mathrm{ACh}$ over basal induced by various agonists was calculated by dividing the fractional release caused by the agonists by the basal release. Statistical analysis was performed using analysis of variance with repeated measures. When significant differences were indicated, post hoc testing was performed using the Scheffe $F$ test. Significance was accepted as $P<0.05$.

\section{RESULTS}

Morphological development. Myenteric plexus neurons derived from neonatal guinea pigs, when grown in serum-containing medium, demonstrated a characteristic pattern of growth. This pattern included a spreading outgrowth zone of proliferating glial cells, peripheral extension of dendrites over the glial cell layer, and progressive formation of elongating aggregates of dendritic processes.

Morphological development in culture occurred in stages. During the first $24 \mathrm{hr}$, explants retained the configuration of the plexuses derived from fresh tissues and attached firmly to culture well coverslips. By $48 \mathrm{hr}$, the mesh-like appearance of plexuses had disappeared and the interstices were filled by ingrowth of glial cells and 
FIG. 1. Photomicrograph of myenteric plexus explant (100× magnification) in $6 \%$ serum-containing medium at $48 \mathrm{hr}$. The plexus is surrounded by a halo of glial cells (closed arrows) with overlying, radially extending dendritic processes (open arrows)

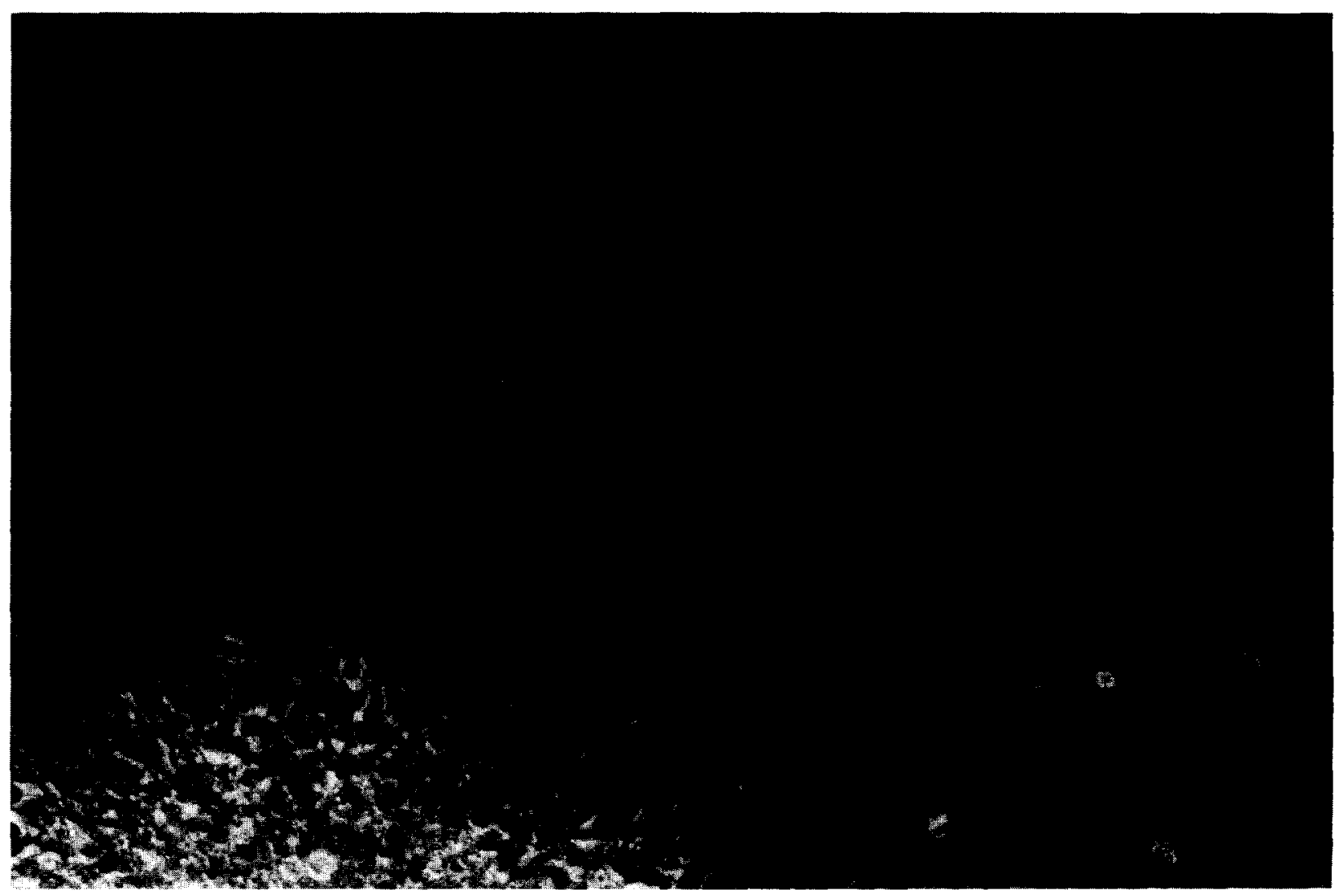

FIG. 2. Photomicrograph (200× magnification) of plexus in Fig. 1 with glial cells (arrows) extending peripherally. 

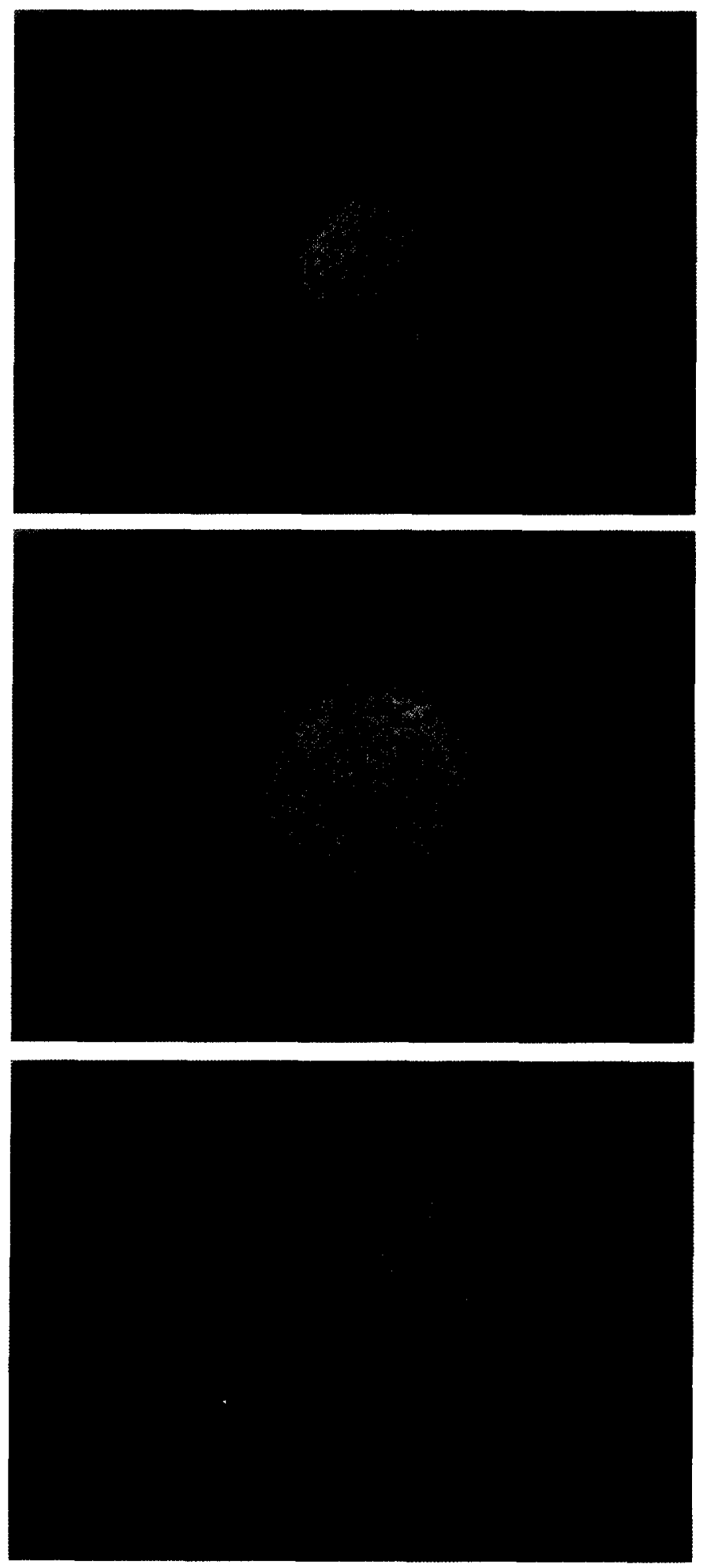

FIG. 3. Myenteric plexus in serum-containing culture medium $(6 \%)$ at $24(\mathrm{~A}), 48(\mathrm{~B})$, and $72 \mathrm{hr}(\mathrm{C})$, illustrating rapid dendritic outgrowth.

neurites. In addition, by $48 \mathrm{hr}$, a continuous ring of proliferating glial cells surrounded the explants and radially oriented dendritic processes could be seen extending from the explant (Figs. 1 and 2). From 48 to $120 \mathrm{hr}$, continued glial cell migration and the rapid formation and elongation of dendrites were apparent (Fig. 3). During this time interval, plexuses became surrounded by a halo of elongating dendrites. Neuronal cells could be maintained in culture for approximately 3 weeks with retention of plexus characteristics.

During the development of the glial outgrowth zone, the plexus perimeter developed a clear monolayer of neuronal cell bodies. Neuronal cell bodies were seen to overlay the glial cell sheet. Long, often branching, dendritic processes were noted to develop simultaneously (Fig. 4). In contrast to previous observations, dendrites were frequently seen to extend beyond the area of glial outgrowth onto the coverslip (Fig. 5). Growth cones could be observed at the tips of extending dendritic processes. Dendritic extension was most rapid between 24 and 72 $\mathrm{hr}$ in culture; continued dendritic extension was not significant beyond $120 \mathrm{hr}$.

Individual neuronal morphology, difficult to assess in plexus explants, due to overlap of cell bodies and dendritic processes, was readily observed in preparations of dispersed neurons. Appearing as rounded, phase bright cells at $12 \mathrm{hr}$ after culture, neurites developed dendritic extensions as early as $24 \mathrm{hr}$. Neurite cell bodies contained eccentrically located nuclei and were approximately $20 \mu \mathrm{m}$ in diameter. Dendritic processes demonstrated growth cones and a fine branching reticular pattern (Fig. 6). Dendritic processes were observed to extend 5 to 10 times the diameter of the cell body.

Morphological development, quantified in terms of dendritic density and mean dendritic length, was dependent upon the presence of serum in the culture medium (Fig. 7). Maximal effects upon dendritic density were noted with a medium containing $6 \%$ serum. Mean dendritic length was also significantly increased in cultures exposed to media containing serum (Fig. 7). Responsiveness to serum was time-dependent ( $\mathrm{Fig}$. 8). Increases in dendritic density and mean dendritic length occurred rapidly between 24 and $72 \mathrm{hr}$, with a plateau in measurements noted subsequently. In addition, increases in dendritic density and mean dendritic length were also noted in the absence of serum, implying the existence of intrinsic serum-independent neurotrophic activity within the explanted tissue (Fig. 7).

Acetylcholine release. Cultured myenteric plexus neurons also demonstrated cholinergic function, as measured by their ability to accumulate labeled choline and to release $\left[{ }^{3} \mathrm{H}\right] \mathrm{ACh}$ in response to specific peptide agonists. Significant increases in $\left[{ }^{3} \mathrm{H}\right] \mathrm{ACh}$ release were noted in response to incubation with cholecystokinin octapeptide, vasoactive intestinal peptide, substance $P$, and calcitonin gene-related peptide (Fig. 9). Significant increases were noted at concentrations as low as $10^{-10}$ $M$, attesting to the sensitivity of the preparation to peptide agonists. 


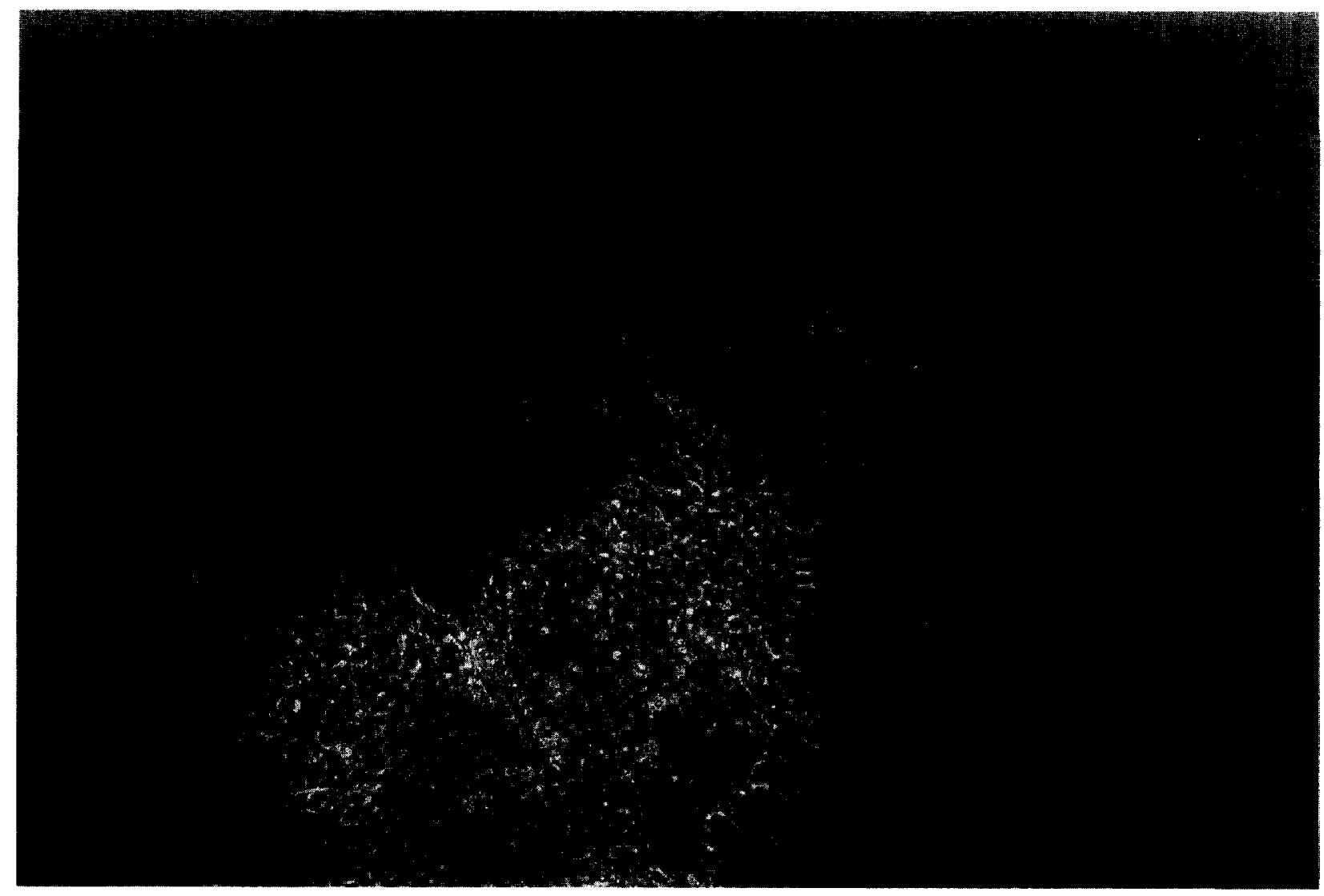

FIG. 4. Elongating dendritic processes (arrows) extending beyond glial cell outgrowth zone at $72 \mathrm{hr}$.

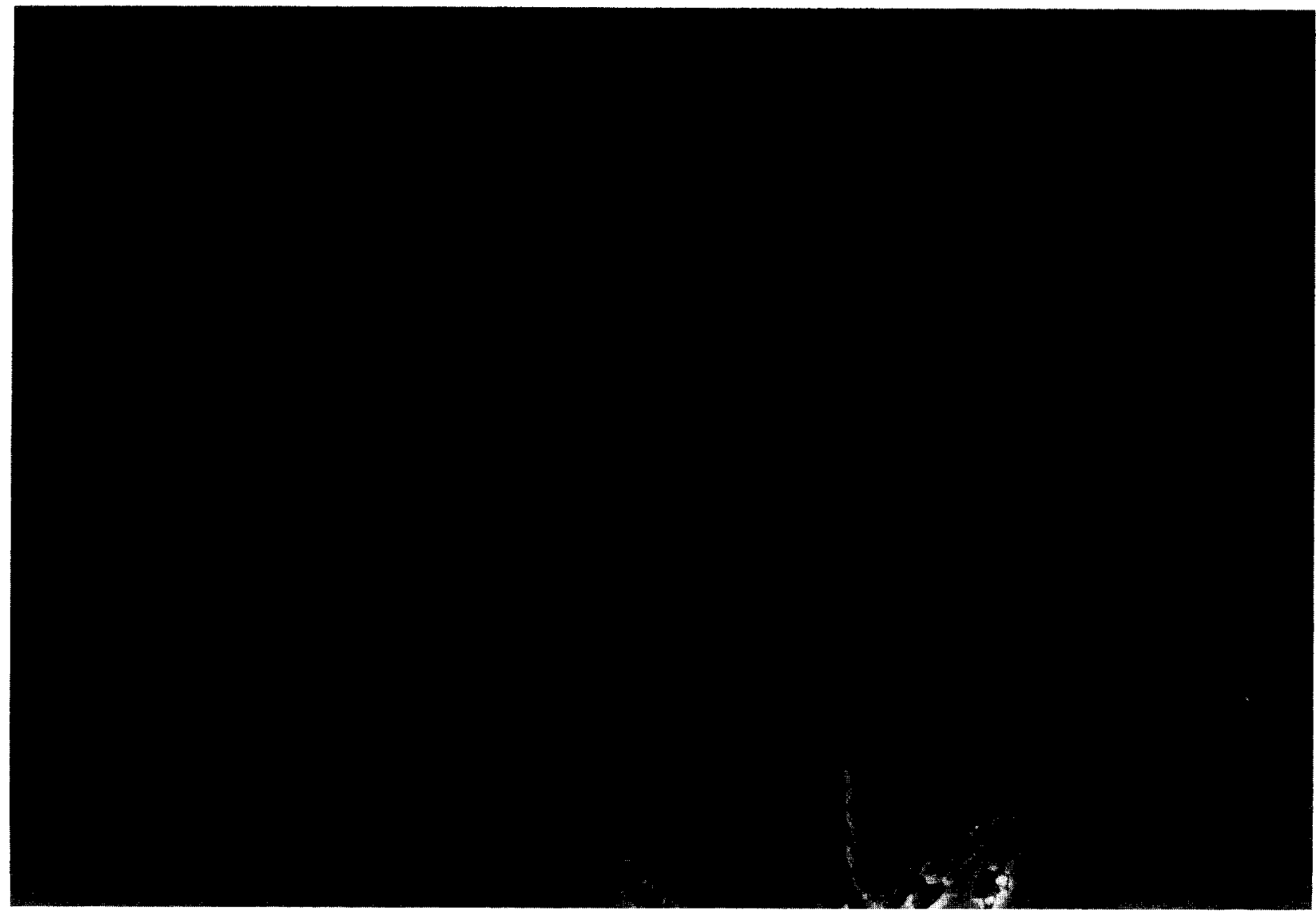

FIG. 5. Dendritic processes growing radially from explanted plexuses often demonstrated a beaded appearance with maximal growth from 24 to $72 \mathrm{hr}$. 

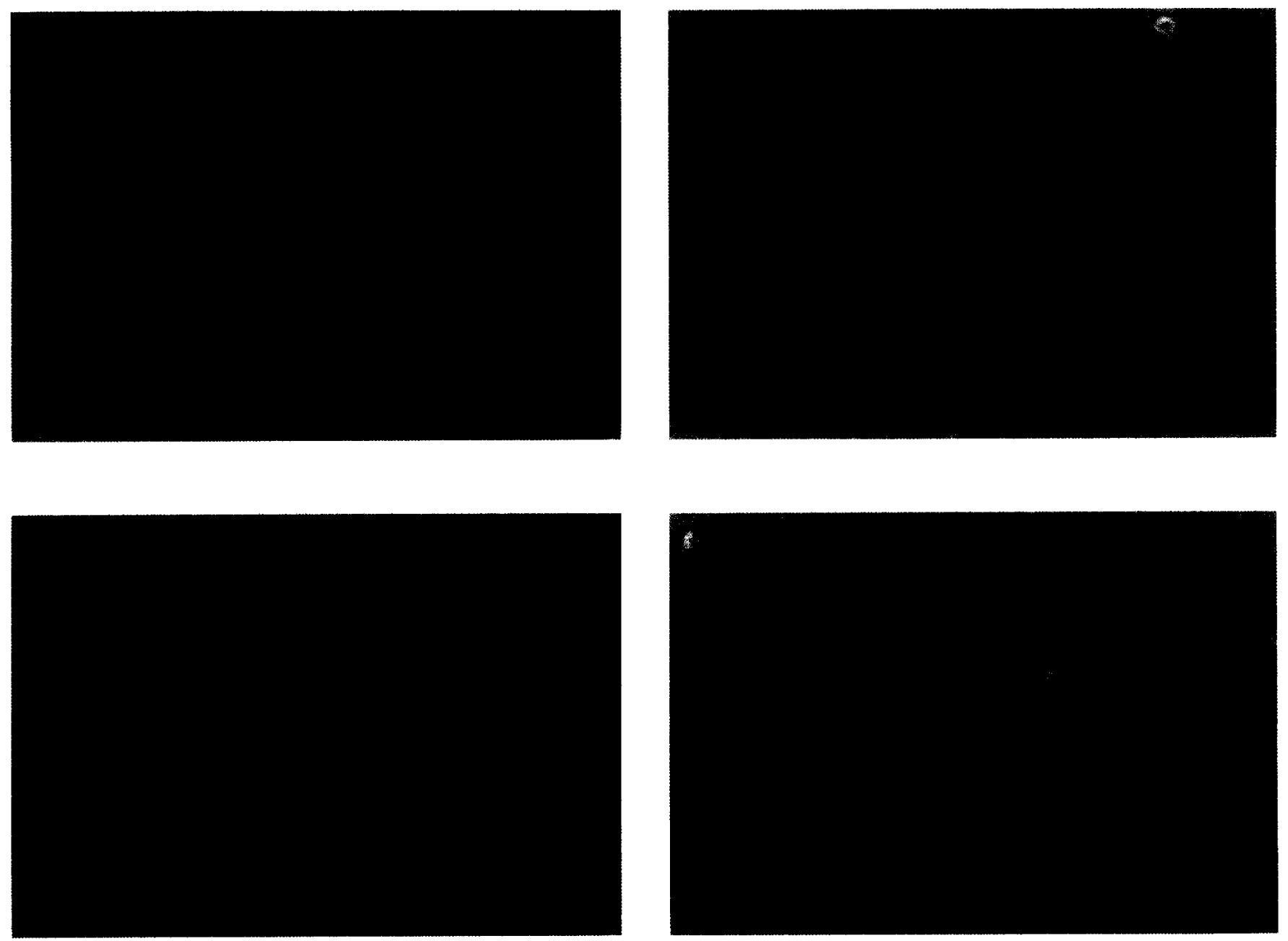

FIG. 6. Photographs (150× magnification) of enteric neurons growing in dispersed form ( $6 \%$ serum at 72 hr). Individual neurons often demonstrated a fine reticular pattern with branching dendritic processes.

\section{DISCUSSION}

The results of the current study confirm that mammalian myenteric plexus neurons can be removed in purified form from the intestine, separated from nonnervous tissues, and held in primary culture for extended periods of time [1, 2]. In culture, the neurons develop morphological characteristics typical of enteric neurons and demonstrate neuronal function, as expressed by cholinergic activity.

Morphological development of plexuses in culture followed a typical pattern. Growth was initiated by the formation of a surrounding ring of glial cells. Dendritic growth was observed within $24 \mathrm{hr}$, initially in association with the underlying glial cells. Dendrites extended from the explants as single fibers, and actively growing dendrites were frequently observed to contain associated growth cones. At later time periods, dendritic extension beyond the outgrowth zone of glial cells was observed.

Increases in dendritic density and mean dendritic length were noted in the absence of serum, implying the existence of intrinsic neurotrophic activity. The importance of glial cells in supporting neurite development has been noted in primary culture of central nervous system neurons [5-7]. Glial cells have been suggested to produce intrinsic neurotrophic substances or to be necessary for processing of exogenous agents $[8,9]$.

Aggregation of dendrites was noted occasionally in older cultures, but organization into distinct fascicles was not observed. The outgrowth pattern in other peripheral (sympathetic) ganglia held in culture is often characterized by the formation of dendritic bundles [ 10 , 11]. The failure of enteric neurons in culture to form such structures has been noted by other investigators [1]. The factors that control formation of enteric ganglia with interconnecting dendritic processes during histogenesis are largely unknown and are an area of potential future investigation.

Morphological development of enteric neurons in culture was serum-responsive. A marked concentration de- 

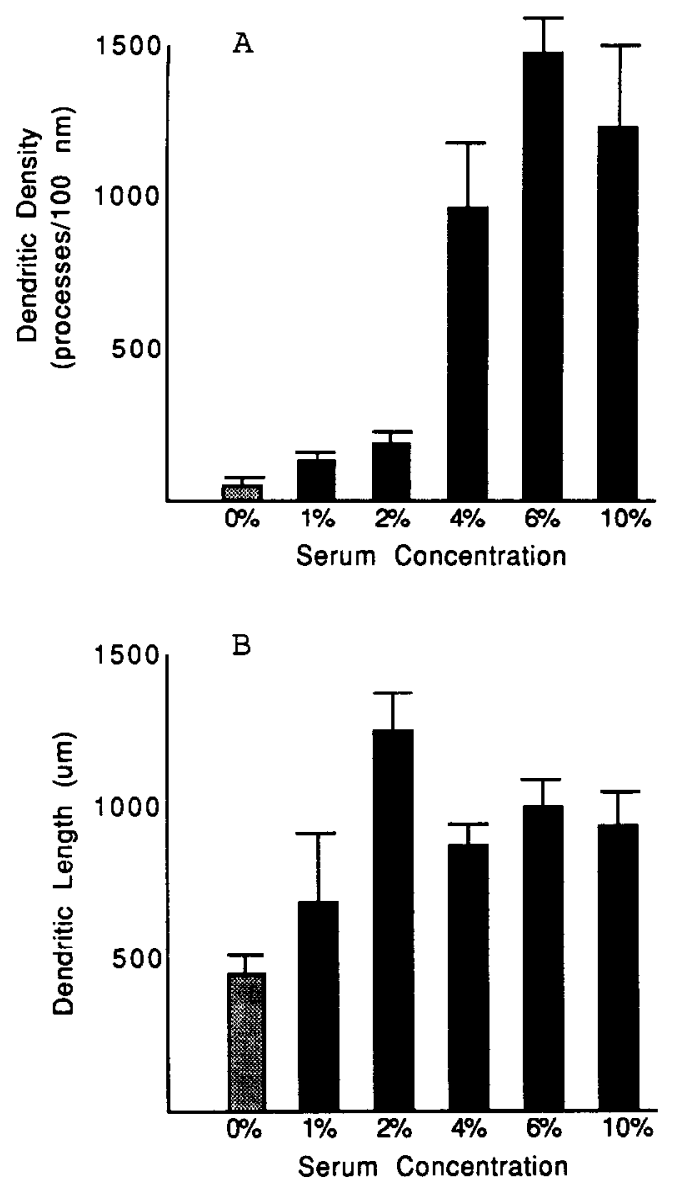

FIG. 7. Dendritic outgrowth in response to serum concentration. Myenteric plexus explants ( $n=6$ each) were exposed to graded concentrations of serum in a defined medium. Quantification of dendritic density (A) and mean dendritic length $(B)$ was performed at 24-hr intervals up to $120 \mathrm{hr}$. Results at $120 \mathrm{hr}$ are illustrated. Significant increases in both parameters were noted for serum concentrations of $2 \%$ and greater.

pendence was noted in terms of dendritic density, suggesting the presence within serum of specific factors that act to stimulate the formation of new dendrites. Maximal responsiveness was noted from 24 to $72 \mathrm{hr}$, with little subsequent dendritic growth, suggesting that trophic activities are exerted for a limited period of time. The nature of agents that may act to stimulate dendritic growth in the enteric nervous system is unknown. Conversely, mechanisms that terminate trophic responsiveness are also undefined. Insulin and related insulin-like growth factors are potential candidates as neurotrophic peptides. Insulin and insulin-like growth factors have been shown to stimulate neurite outgrowth in cultured sympathetic neurons, in neuroblastoma cell lines, and in selected central nervous system tissues [12-15]. Nerve growth factor and related peptides are also trophic to a wide spectrum of nervous tissues [16,17]. The activity of these agents in the myenteric plexus is, however, not documented. The ability to quantify trophic actions us- ing cultured enteric neurons should permit investigation of these and other trophic agents.

Myenteric plexus neurons in culture exhibited cholinergic activity, indicating that functional development in addition to morphological development may occur in vitro. Dose-dependent increases in labeled $\mathrm{ACh}$ release were noted upon incubation with a variety of peptide agonists. The ability to respond to exogenous peptides was noted at concentrations as low as $10^{-10} M$. In general, the use of higher concentrations of peptide agonists have been reported by investigators utilizing tissue preparations in which mechanical or enzymatic treatments have been used immediately prior to study. Perhaps time in culture allows membrane receptors, susceptible to damage during enzymatic treatment, to regenerate.

In summary, enteric neurons can be maintained in primary culture with predictable morphological development and functional characteristics. The culture system seems well adapted to in vitro study of enteric neural control mechanisms and has promise for investigation of important aspects of digestive function.
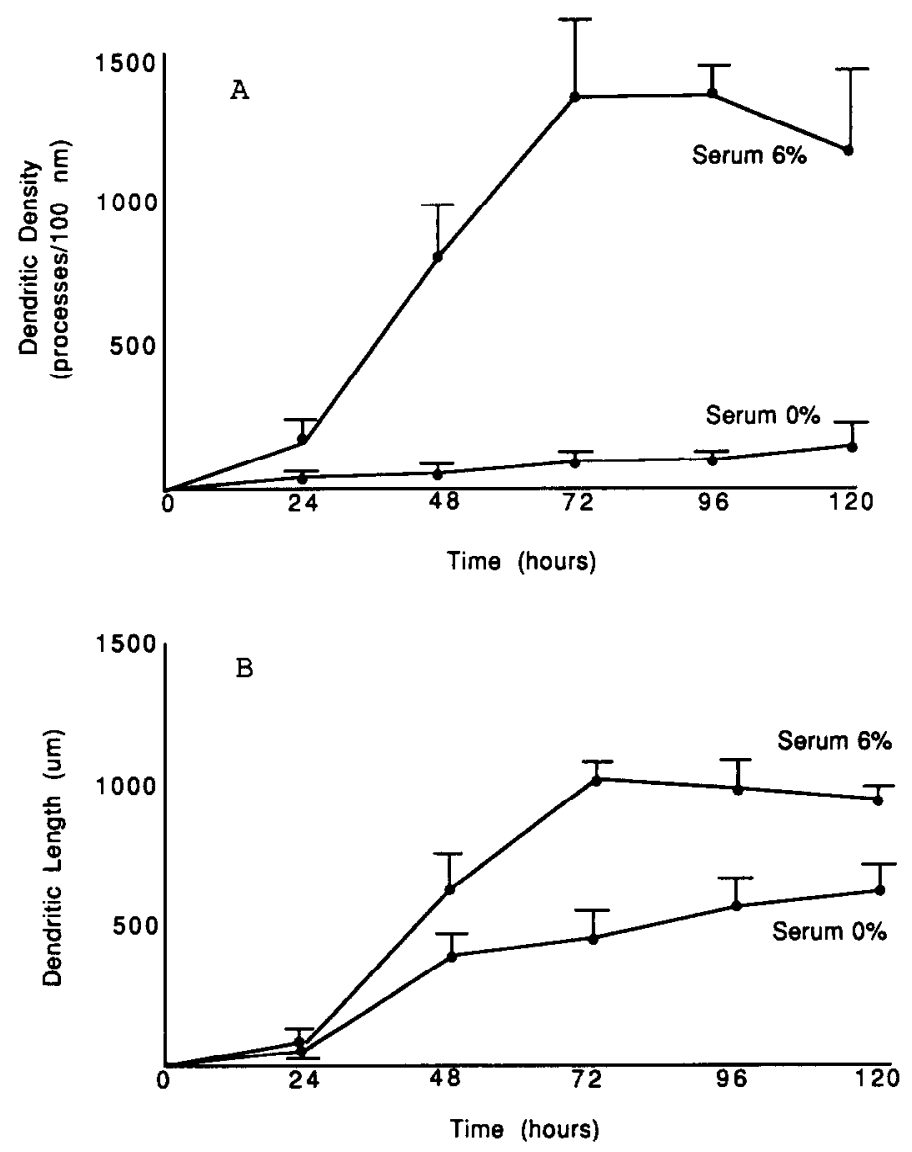

FIG. 8. Dendritic outgrowth expressed in terms of dendritic density (A) and mean dendritic length (B) at times from 0 to $120 \mathrm{hr}$ for myenteric plexus explants exposed to defined medium in the absence or presence of serum $(6 \%)$. For each condition, $n=6$. Significant differences relative to $0 \%$ serum were noted at all time points from 48 to $120 \mathrm{hr}$. 


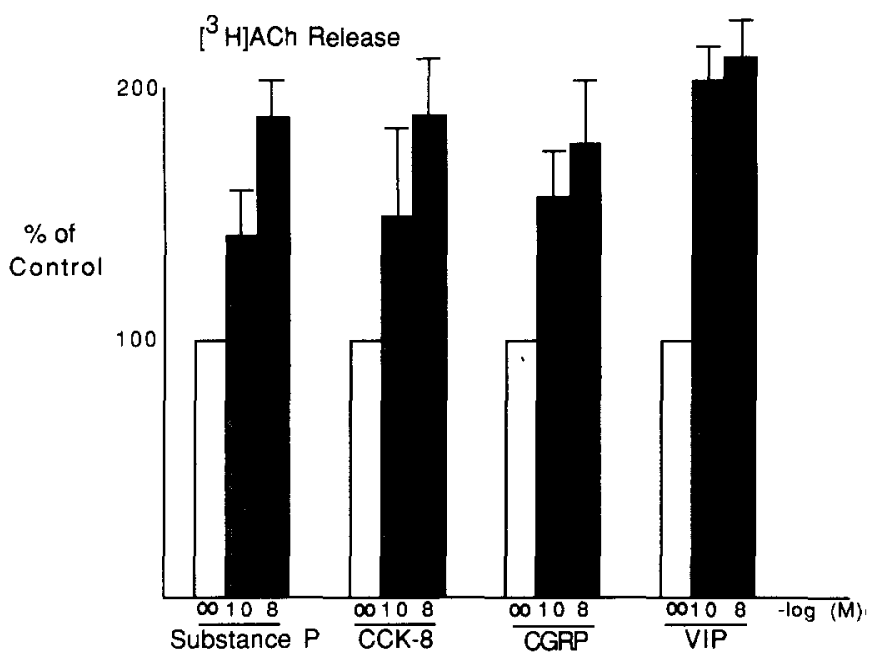

FIG. 9. Tritiated $\mathrm{ACh}$ release from myenteric plexus explants ( $n$ $=6$ to 8 ) exposed to $6 \%$ serum for $120 \mathrm{hr}$ in response to substance $\mathrm{P}$, CCK-8, CGRP, or VIP at the concentrations shown.

\section{REFERENCES}

1. Jessen, K. R., Saffrey, M. J., and Burnstock, G. The enteric nervous system in tissue culture. I. Cell types and their interactions in explants of the myenteric plexus and submucous plexuses from guinea pig, rabbit and rat. Brain Res. 262: 17, 1983.

2. Bannerman, P. G. C., Mirsky, R., and Jessen, K. R. Establishment and properties of separate cultures of enteric neurons and enteric ganglia. Brain Res. 440: 99, 1988.

3. Jessen, K. R., McConnell, J. D., Purves, R. D., et al. Tissue culture of mammalian enteric neurons. Brain Res. 152: 573, 1978.

4. Mulholland, M. W., and Jaffer, S. Stimulation of acetylcholine release in myenteric plexus by calcitonin gene-related peptide. Am. J. Physiol. 259: G934, 1990.

5. Aizenman, Y., and de Vellis, J. Brain neurons develop in a serum and glial free environment: Effects of transferrin, insulin, insu- lin-like growth factor-I and thyroid hormone on neuronal survival, growth and differentiation. Brain Res. 406: 32, 1987.

6. Saneto, R., and de Vellis, J. Characterization of cultured rat oligodendrocytes proliferating in a serum-free, chemically defined medium. Proc. Natl. Acad. Sci. USA 82: 3509, 1985.

7. Morrison, R.S., and de Vellis, J. Growth of purified astrocytes in a chemically defined medium. Proc. Natl. Acad. Sci. USA 73: $7205,1981$.

8. Muller, H. W., and Seifert, W. A neurotrophic factor (NTF) released from primary glial cultures supports survival and fiber outgrowth of cultured hippocampal neurons. J. Neurosci. Res. 8: 195, 1982.

9. Patterson, P. Environmental determination of autonomic neurotransmitter functions. Annu. Rev. Neurosci. 1: 1, 1978.

10. Chamley, J. H., Mark, G. E., Campbell, G., and Burnstock, G. Sympathetic ganglia in culture. I. Neurons. Z. Zellforsch 135: $287,1972$.

11. Hill, C. E., and Burnstock, G. Amphibian sympathetic ganglia in culture. Cell Tissue Res. 162: 209, 1975.

12. McMorris, F. A., Smith, T. M., DeSalvo, S., and Furlanetto, R. W. Insulin-like growth factor I/somatomedin C: A potent inducer of oligodendrocyte development. Proc. Natl. Acad. Sci. USA 83: 822, 1986.

13. Recio-Pinto, E., Rechler, M. M., and Ishii, D. N. Effects of insulin, insulin-like growth factor II, and nerve growth factor on neurite formation and survival in cultured sympathetic and sensory neurites. J. Neurosci. 6: 1211, 1986.

14. Lenoir, D., and Honegger, P. Insulin-like growth factor I (IGF I) stimulates DNA synthesis in fetal rat brain cell cultures. Dev. Brain Res. 7: 205, 1983.

15. Puro, D. G., and Agardh, E. Insulin-mediated regulation of neuronal maturation. Science 225: 1170, 1984.

16. Mill, J. F., Chao, M. V., and Ishii, D. N. Insulin, insulin-like growth factor II, and nerve growth factor effects on tubulin mRNA levels and neurite formation. Proc. Natl. Acad. Sci. USA 82: 7126, 1985.

17. Martinez, H. J., Dreyfus, C. F., Jonakait, G. M., and Black, I. B. Nerve growth factor promotes cholinergic development in brain striatal cultures. Proc. Natl. Acad. Sci. USA 82: 7777, 1985. 